\title{
Heat Transfer Performance of a Novel Microchannel Embedded with Connected Grooves
}

\author{
Ding Yuan ${ }^{1}$, Wei Zhou ${ }^{1 *} \mathbb{D}$, Ting Fu² and Qingyu Dong ${ }^{1}$
}

\begin{abstract}
To improve the heat transfer performance of microchannels, a novel microchannel embedded with connected grooves crossing two sidewalls and the bottom surface (type A) was designed. A comparative study of heat transfer was conducted regarding the performances of type A microchannels, microchannels embedded with grooves on their bottom (including types B and C), or on the sidewalls (type D) as well as smooth rectangular microchannels (type E) via a three-dimensional numerical simulation and experimental validation (at Reynolds numbers from 118 to 430). Numerical results suggested that the average Nusselt number of types $A, B, C$, and D microchannels were 106 , $73.4,50.1$, and $12.6 \%$ higher than that of type E microchannel, respectively. The smallest synergy angle $\beta$ and entropy generation number $N_{s, a}$ were determined for type A microchannels based on field synergy and nondimensional entropy analysis, which indicated that type A exhibited the best heat transfer performance. Numerical flow analysis indicated that connected grooves induced fluid to flow along two different temperature gradients, which contributed to enhanced heat transfer performance.
\end{abstract}

Keywords: Microchannel, Connected grooves, Heat transfer enhancement, Performance evaluation

\section{Introduction}

Since Tuckerman et al. [1] proposed microchannel heat sinks, the study of microchannels has attracted the attention of many researchers. Microchannels are widely used in electronic products, micro reactors and other fields due to their high heat transfer efficiency and compact structure [2]. It is known that fluid in a microchannel is dominated by laminar flow, therefore, many scientists and engineers are devoted to improving the heat transfer performance of microchannels. Current enhanced heat transfer technologies for microchannels are classified as either passive or active. Active technology takes advantage of external energy input, such as jet technology [3, 4], extra magnetic fields [5], electric fields [6], acoustic

\footnotetext{
*Correspondence: weizhou@xmu.edu.cn

${ }^{1}$ Department of Mechanical and Electrical Engineering, Xiamen

University, Xiamen 361005, China

Full list of author information is available at the end of the article
}

fields [7, 8], or piezoelectric actuation [9]. However, because of the inherent complicated structures, there are some disadvantages for active technologies, such as their expense or inconvenience in mass production.

Passive technology entails less expense and more convenient fabrication than an active one while achieving desirable heat transfer performance without any extra power consumption except pumping power. Passive technological development mainly includes enhancing the working fluid and improving microchannel structure. Nanofluids are one kind of enhanced working fluids that contain highly thermally conductive nanoparticles, such as carbon, metal, and metal oxides. Compared to the base fluid, nanofluid has excellent properties such as higher thermal conductivities and significant enhancement of heat transfer performance. This has motivated many researchers to investigate flow and heat transfer performance in microchannel heat sinks with nanofluids. A number of researchers [10-16] have reported nanofluid 
enhanced heat transfer performance in mini/microchannel heat sinks. However, Anoop et al. [17] concluded that the heat transfer performance of nanofluids deteriorated at high flow rates compared to water. Rimbault et al. [18] observed clear heat transfer degradation for $4.5 \%$ (volume fraction) nanofluids, although with a slight heat transfer enhancement for low particle volume fractions (0.24 and $1.03 \%)$. Moreover, Khoshvaght-Aliabadi et al. [19] compared their results with those of Fan et al. [20], Ho et al. [15], and Sohel et al. [16] and concluded that an enhanced surface was more effective than using an enhanced working fluid, such as a nanofluid, from the viewpoint of thermodynamics. Furthermore, microchannels with enhanced surfaces are more stable and reliable during working compared to enhanced working fluid.

An effective passive technology for improving microchannel structure is enhanced surfaces, which includes varying sectional microchannels [21, 22], double-layered microchannels [23, 24], changing flow direction [25, 26], adding grooves on the side or bottom wall of microchannels [27-31], and longitudinal vortex generators [32, 33]. The above mentioned methods can effectively enhance heat transfer performance and produce better overall performance. The heat transfer enhancement mechanism applied in enhanced surface techniques can be concluded to be mainly: (1) extending heat transfer areas, (2) interrupting thermal and hydrodynamic boundary layers, and (3) improving convection or reducing temperature gradients via vortices.

Grooves are usually embedded into a microchannel because they can induce flow perturbation which plays an important role in heat transfer performance enhancement. Conder et al. [28] found that deep grooves enhanced the overall heat transfer coefficient, while shallower shapes had less effect. Moderately deep grooves resulted in nearly $75 \%$ greater average convective heat transfer coefficient with approximately $35 \%$ greater pressure penalty from turbulent conditions. Chai et al. [29] explored the optimal structure and heat transfer characteristics of grooves with the help of computational fluid dynamics in microchannels. Solovitz et al. [30] investigated the relationships of flow feature and groove structure with the help of particle image velocimetry. They suggested that the optimal shape involved a deeper groove, with enhancements greater than $35 \%$ for depthto-width ratios between 0.3 and 0.5 .

From the above studies, previous research has mainly focused on the influence of sidewall or bottom grooves on heat transfer performance. However, little attention has been paid to connected grooves crossing sidewalls and the bottom surface. Connected grooves inside a microchannel might change the flow in the sidewall and induce intensely radial and transverse convection along temperature gradients in the microchannel. Guo et al. $[34,35]$ indicated that guiding flow along temperature gradients was advantageous for improving heat transfer in a laminar flow field. Therefore, connected grooves are a promising passive technique for heat and mass transfer enhancement and has been applied to a passive mixer. Yang et al. [36] studied the application of connected grooves in a micro mixer experimentally. Their results showed that connected grooves induced an intensely transverse field of fluid and thus generated significant mixing enhancement in the micro mixer. Their work indicated that the study of the application of connected grooves in microdevices was very important and inspired us to examine the introduction of connected grooves into a microchannel system, which could guide fluid flow along temperature gradients (radial and transverse of a microchannel). It was important to understand the effects of connected grooves on the heat transfer performance in the microchannel heat sink. However, investigations on this topic have been relatively rare, and more focus on this topic is required. The present study focused on the effects of connected grooves on fluid flow and heat transfer performance in a microchannel heat sink. In particular, a detailed analysis and evaluation of the overall performance of connected grooves in a microchannel heat sink was performed from the viewpoint of flow path and the first and second law of thermodynamics.

\section{Model Descriptions}

\subsection{Geometric Configurations}

The model diagram and geometric parameters of different microchannels are shown in Figure 1 . The width $W_{\text {ch }}$ of a microchannel was $1.5 \mathrm{~mm}$, depth $H_{\mathrm{ch}}$ at $0.75 \mathrm{~mm}$, and corresponding hydraulic diameter at $1 \mathrm{~mm}$, thus

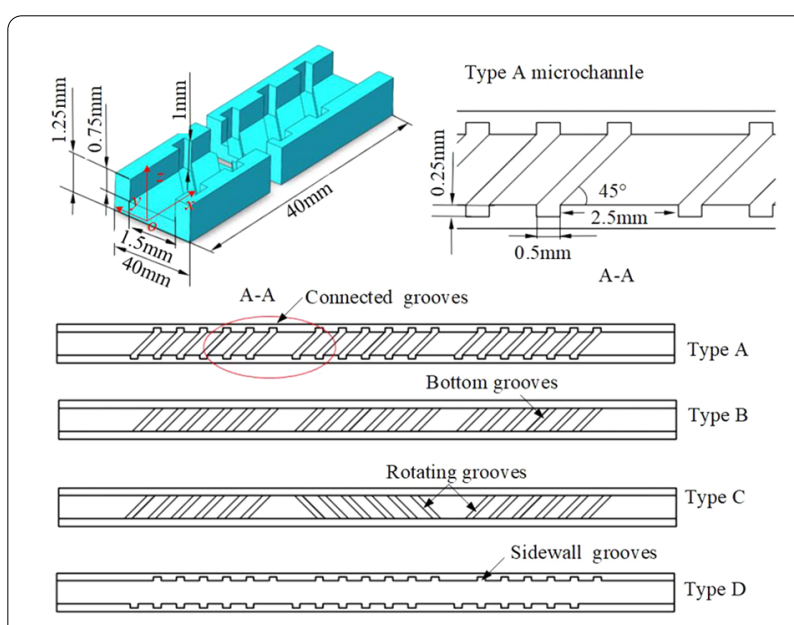

Figure 1 Structural design of four microchannels embedded with different grooves 
being a microchannel. The length $L$ of a microchannel was $40 \mathrm{~mm}$, wall thickness $t$ at $0.5 \mathrm{~mm}$, groove depth at $0.25 \mathrm{~mm}$, and inclined angle of the bottom groove at $45^{\circ}$. The spacing of each groove in a group was $1 \mathrm{~mm}$ and the spacing of each group $2.5 \mathrm{~mm}$. All samples were labeled as follows: type A (connected groove microchannel), type $\mathrm{B}$ (bottom groove microchannel), type $\mathrm{C}$ (rotating groove microchannel), type D (side-wall groove microchannel), and type $\mathrm{E}$ (smooth rectangular microchannel).

\subsection{Governing Equations and Boundary Conditions}

In this study, one microchannel was selected for simulation due to the symmetry of the microchannel heat sink. A solid-fluid coupling model was employed, with copper as a solid domain and deionized water the fluid domain. Fluid-solid domain interface boundary conditions were applied on the interfaces between the domains. At the microchannel inlet $(x=0)$, a uniform velocity $\left(u_{\text {in }}=0.08\right.$ $0.36 \mathrm{~m} / \mathrm{s})$, and temperature $\left(T_{\text {in }}=298 \mathrm{~K}\right)$ were employed. A uniform heat flux, $\left(q_{\mathrm{w}}=100 \mathrm{~kW} / \mathrm{m}^{2}\right)$ was applied on the bottom of the microchannel heat sink $(z=0)$. At the microchannel outlet $(x=40 \mathrm{~mm})$, the pressure-outlet boundary condition was adopted, and $P_{\text {out }}$ set as zero. All other walls were assigned adiabatic and no-slip boundary conditions. Structured grids and a local mesh refinement method were applied for all microchannels. The computational grid for a type A microchannel is shown in Figure 2.

Numerical calculations were based on some assumptions, including: (1) single-phase incompressible laminar flow; (2) continuous and steady flow; (3) heat radiation and volume force were ignored; (4) fluid viscosity was a function of temperature, while the other physical parameters of solid and fluid were constant; and (5) viscous dissipation was ignored.

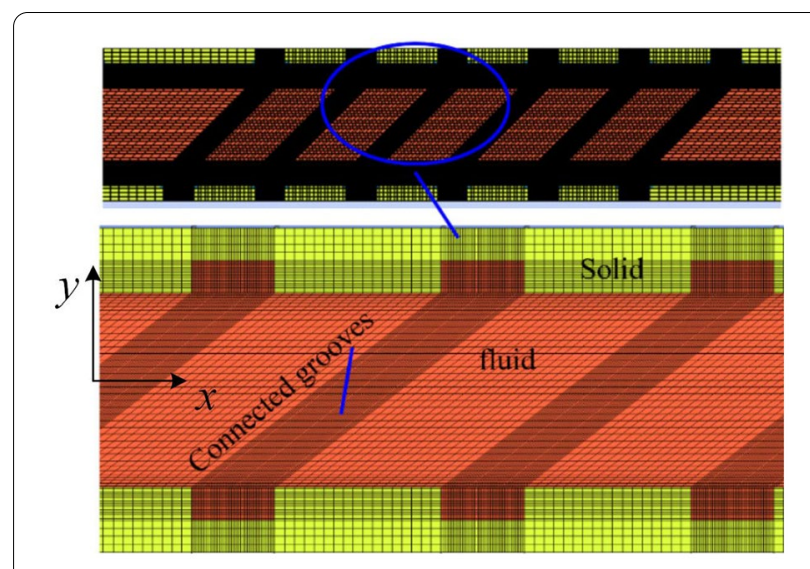

Figure 2 Computational grid for a type A microchannel
The corresponding continuity equation, momentum equations, and energy equation of the fluid domain were obtained as Eqs. (1)-(3), expressed as

$$
\begin{aligned}
& \nabla U=0, \\
& \rho(U \nabla U)=-\nabla p+\nabla(\mu \nabla U), \\
& \rho c_{p}\left(U \nabla T_{f}\right)=\lambda_{f} \nabla^{2} T_{f} .
\end{aligned}
$$

For the solid region, only the energy equation was considered for heat transfer analysis, as its velocity was 0 , shown as

$$
\lambda_{s} \nabla^{2} T_{s}=0,
$$

where subscripts $f$ and $s$ denote fluid and solid, respectively; $U$ the fluid velocity, in $\mathrm{m} / \mathrm{s} ; P$ the pressure, in $\mathrm{Pa} ; T$ the temperature, in K; $\rho$ the fluid density, in $\mathrm{kg} / \mathrm{m}^{3} ; c_{p}$ the specific heat, in $\mathrm{J} /(\mathrm{kg} \cdot \mathrm{K}) ; \lambda$ the thermal conductivity, in $\mathrm{W} /(\mathrm{m} \cdot \mathrm{K})$; and $\mu$ the viscosity, in Pa.s. The $\mu$ is a function of temperature, expressed as Eq. (5) [22], as

$$
\mu(T)=2.414 \times 10^{-5} \times 10^{\frac{247.8}{T-140}} .
$$

\subsection{Solution Methods and Grid Independence Test}

The governing equations were discretized and solved by second-order upwind and the SIMPLEC algorithm of the FLUENT software, with a convergence residual of $10^{-6}$. Grid independence verification was used to test the influence of varied grid numbers on calculation results. Taking type $\mathrm{B}$ as an example, structured grids and a local mesh refinement method were used and the wall part encrypted. Three grid sizes were selected for independence tests, including grid numbers at 0.8 million (sparse), 1.5 million (dense), and 1.8 million (extremely dense). The average pressure drop and the average Nusselt number $(\mathrm{Nu})$ were calculated at $u_{\text {in }}=0.36 \mathrm{~m} / \mathrm{s}$. Deviations of average pressure drop using 0.8 and 1.5 million grids from that of 1.8 million grids were $7.2 \%$ and $2.3 \%$, respectively. Deviations of $\mathrm{Nu}$ using 0.8 and 1.5 million grids from that of 1.8 million grids were $5.3 \%$ and $1.5 \%$, respectively. Therefore, 1.5 million grids was employed for the type B microchannel.

\section{Data Reduction}

The Reynolds number $(R e)$ and hydraulic diameter $\left(D_{\mathrm{h}}\right)$ were calculated using Eqs. (6) and (7), respectively, as

$$
R e=\frac{\rho u_{i n} D_{h}}{\mu(T)}
$$




$$
D_{\mathrm{h}}=\frac{2 W_{c h} H_{c h}}{W_{c h}+H_{c h}}
$$

where $W_{c h}$ and $H_{c h}$ are the microchannel width and height, respectively.

The average friction coefficient $f$ and pressure drop $\Delta p$ at the microchannel inlet and outlet were calculated using Eqs. (8) and (9), respectively, as

$$
\begin{aligned}
& f=\frac{\Delta P D_{h}}{2 \rho u^{2} L_{c h}} \\
& \Delta P=P_{\text {in }}-P_{\text {out }}
\end{aligned}
$$

where $L_{c h}$ is the microchannel length, $P_{\text {in }}$ and $P_{\text {out }}$ the inlet and outlet pressure, respectively. The average $\mathrm{Nu}$ was expressed as Eq. (10).

$$
N u=\frac{Q_{t o t} D_{h}}{\lambda_{f . m} A_{t}\left[T_{w}-0.5\left(T_{\text {in }}+T_{\text {out }}\right)\right]},
$$

where $Q_{t o t}$ is the total heat flow, $Q_{t o t}=q \times A_{w} ; A_{w}$ is the heating area; $T_{w}$ is the temperature of the heat sink bottom; $A_{t}$ is the solid-fluid interface area, and $T_{\text {out }}$ is the mass weighted average temperature at the outlet.

The effective energy removed by the working fluid, $Q_{e f f}$ was obtained from Eq. (11).

$$
Q_{\text {eff }}=c_{p} \dot{m}\left(T_{\text {out }}-T_{\text {in }}\right),
$$

where $\dot{m}$ is the mass flow rate.

$\overline{T_{w}}$, the average wall temperature of microchannel, was defined as Eq. (12).

$$
\overline{T_{w}}=\frac{T_{w, 1}+T_{w, 2}+T_{w, 3}+T_{w, 4}+T_{w, 5}}{5},
$$

where $T_{w, i}$ is given as

$$
T_{w, i}=T_{i}-Q_{e f f}\left(\frac{l_{c u}+l_{h s}}{\lambda_{s} A_{t}}\right),(i=1,2, \ldots, 5) .
$$

The comprehensive evaluation factor $P E C$ was defined as

$$
P E C=\frac{N u / N u_{0}}{\left(f / f_{0}\right)^{1 / 3}},
$$

where $N u_{0}$ and $f_{0}$ are the average $N u$ and friction coefficient of the smooth rectangular microchannel, respectively.

The thermal resistance $R_{\mathrm{T}}$ of the microchannel was defined as

$$
R_{\mathrm{T}}=\frac{T_{w, \max }-T_{i n}}{q A_{w}},
$$

where $T_{\text {w max }}$ is the maximum temperature on the heat sink bottom, in $\mathrm{K}$, and $A_{w}$ the heating surface of the microchannel.

The field-synergy angles $\beta$ [35] of heat transfer of different microchannels was defined as Eq. (16).

$$
\beta=\operatorname{arcos} \frac{\vec{U} \cdot \nabla T}{|\vec{u}| \cdot|\nabla T|},
$$

where the smaller the $\beta$ is, the better the synergistic effect of the temperature and velocity fields will be.

Due to the irreversible processes of heat transfer and flow, the temperature entropy production $S_{T}$ and flowing entropy production $S_{P}$ were defined as Eqs. (17) and (18), respectively.

$$
\begin{gathered}
S_{T}=\iiint_{\Omega} \frac{\lambda_{f}}{T_{f}^{2}}\left[\left(\left(\frac{\partial T_{f}}{\partial x}\right)^{2}+\left(\frac{\partial T_{f}}{\partial y}\right)^{2}+\left(\frac{\partial T_{f}}{\partial z}\right)^{2}\right)\right] \mathrm{d} v, \\
S_{P}=\iiint_{\Omega} \frac{\mu}{T_{f}}\left[\begin{array}{l}
2\left(\left(\frac{\partial u}{\partial x}\right)^{2}+\left(\frac{\partial v}{\partial y}\right)^{2}+\left(\frac{\partial w}{\partial z}\right)^{2}\right) \\
+\left(\frac{\partial u}{\partial y}+\frac{\partial v}{\partial x}\right)^{2}+\left(\frac{\partial u}{\partial z}+\frac{\partial w}{\partial x}\right)^{2}+\left(\frac{\partial v}{\partial z}+\frac{\partial w}{\partial y}\right)^{2}
\end{array}\right] \mathrm{d} v,
\end{gathered}
$$

where $u, v$, and $w$ are the components of the velocity function in $x, y$, and $z$-directions, in $\mathrm{m} / \mathrm{s}$. The total entropy production $S$ was calculated as Eq. (19).

$$
S=S_{T}+S_{P} .
$$

The dimensionless entropy production was calculated as Eq. (20).

$$
S_{T}^{*}=\frac{S_{T}}{\dot{m} c_{p}}, S_{p}^{*}=\frac{S_{P}}{\dot{m} c_{p}}, S^{*}=\frac{S_{P}+S_{T}}{\dot{m} c_{p}},
$$

where $\dot{m}$ is the mass flow; $S_{T}^{*}$ is the dimensionless temperature entropy; $S_{P}^{*}$ is the dimensionless flow entropy, and $S^{*}$ is the dimensionless total entropy.

\section{Results and Discussion}

\subsection{Validation with Experimental Data}

The accuracy and reliability of the numerical solution was validated by conducting an experiment to examine the single-phase laminar heat transfer of type B microchannels. A schematic of the flow loop and picture of the experimental setup are shown in Figure 3(a) and (b), respectively. Deionized water was used as the working fluid and circulated through the flow loop by a gear pump (GAT23-DB-380B, Micropump Inc., Vancouver, WA, USA) from the liquid reservoir. The test loop water flowed through a flowmeter with an uncertainty of $2.5 \%$. After exiting the flow meter, the water passed through 


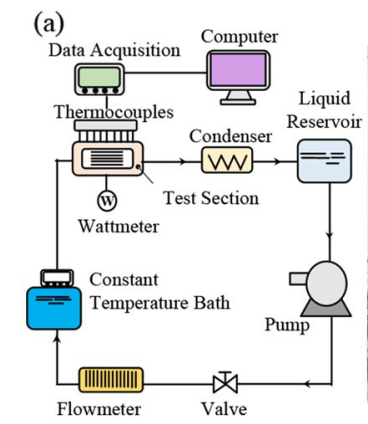

(b)

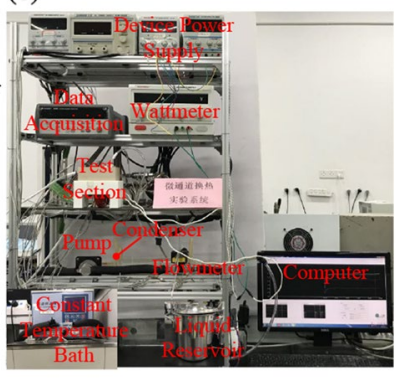

Figure 3 Convective heat transfer performance test system: schematic diagram of flow loop (a) and experimental setup (b)

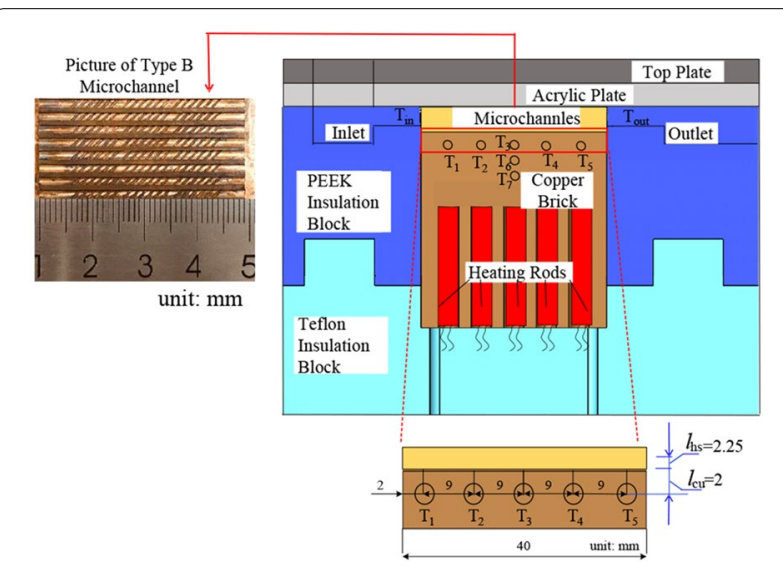

Figure 4 Schematic of the microchannel heat sink test section

a constant temperature water bath where the water was maintained to the desired test section inlet temperature with an uncertainty of $0.1{ }^{\circ} \mathrm{C}$. Leaving the test section, the water flowed through a condenser where the water was cooled and then returned to the liquid reservoir.

The test section consisted of a microchannel sample, top plate (stainless steel), acrylic plate, polyether ether ketone flow housing, Teflon insulation block, 9 heating rods, and heating copper brick (Figure 4). The sample containing 8 type $\mathrm{B}$ microchannels was manufactured using numerical control milling. The heating copper brick with cartridge heaters inside consisted of an upper rectangular section of $20 \mathrm{~mm} \times 40 \mathrm{~mm}$, which was identical to the backside surface of the microchannel sample. The microchannel sample was adhered on top of the copper block using a very thin layer of heat-conducting silicon grease to minimize contact thermal resistance. Nine cartridge heaters, connected to a digital power-meter, supplied a total power of $80 \mathrm{~W}$ to the test section. Five K-type thermocouples with an uncertainty of $0.3{ }^{\circ} \mathrm{C}$ were embedded in the copper brick at a distance of $2 \mathrm{~mm}$ below the top surface of copper brick to measure the wall

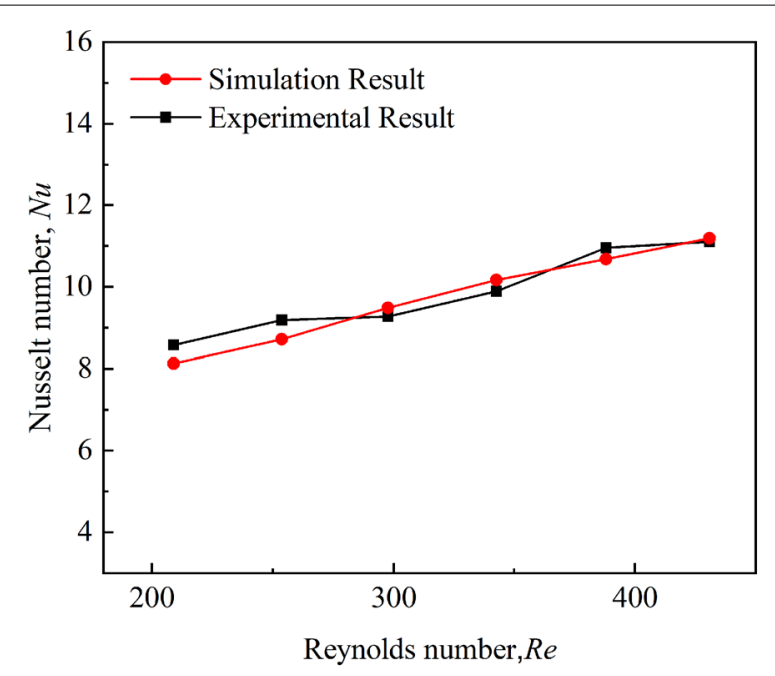

Figure 5 Comparison between experimental and simulation results for the average $\mathrm{Nu}$ of type B microchannel

temperature distribution of microchannels $\left(\mathrm{T}_{1}-\mathrm{T}_{5}\right)$. Two K-type thermocouples $\left(\mathrm{T}_{6}-\mathrm{T}_{7}\right)$ were used to measure the thermal conductivity of the heating copper brick according to the one dimensional Fourier heat conduction law. The locations of these seven thermocouples are depicted in Figure 4. The inlet and outlet temperatures were detected by two type-K thermocouples, which were set at about $5 \mathrm{~mm}$ before and after the microchannel sample. All temperatures and flow rates were collected by an Agilent 34970A data acquisition system (Agilent Technologies, Inc., Santa Clara, CA, USA).

Experiments were conducted with an inlet temperature of $25{ }^{\circ} \mathrm{C}$ and heat fluxes of $100 \mathrm{~kW} / \mathrm{m}^{2}$. In each test, the supplied power and inlet temperature were constant and different $R e$ numbers (208-430) was obtained by adjusting the flow rates. A comparison between experimental and numerical average $N u$ for type B microchannel showed that differences of $\mathrm{Nu}$ between the simulated results and tested data were within $5 \%$, indicating the numerical solution here was reliable (Figure 5).

\subsection{Flowing Analysis}

It is known that fluid flow has an important influence on heat transfer performance. An effective method for enhancing heat transfer is fabricating grooves at the microchannel bottom, because the resulting vortices could promote fluid to flow along the temperature gradients. In this part of the study, the enhanced heat transfer mechanism of grooved microchannels was further investigated by examining the streamlines of the different microchannels. The streamlines were intercepted from $x=11.4$ to $20.4 \mathrm{~mm}$ for analysis (Figure 6). The 


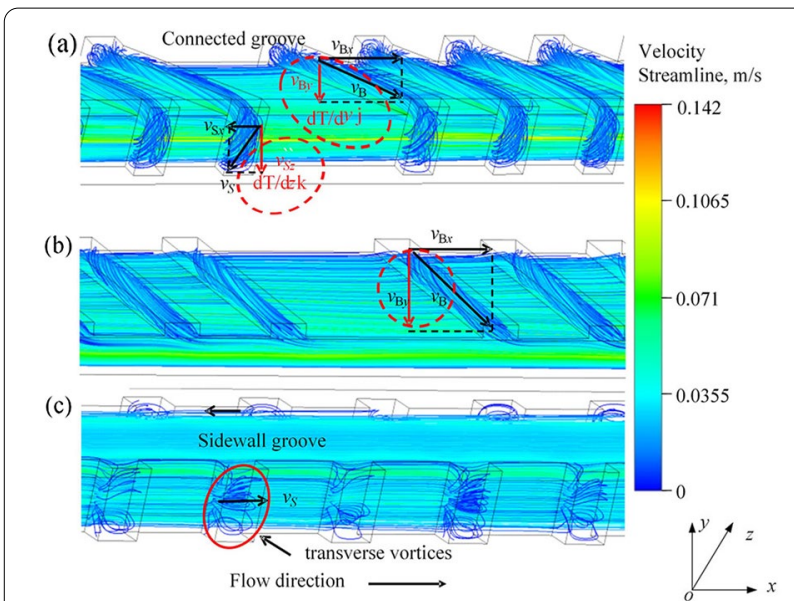

Figure 6 Streamlines of different microchannels at $R e=120$, types A, $B$, and $D((\mathbf{a}-\mathbf{c})$, respectively)

streamline of type A showed that the total velocity $v_{\mathrm{B}}$ in the bottom groove of type A could be decomposed into $v_{\mathrm{Bx}}$ and $v_{\mathrm{By}}$, with $v_{\mathrm{By}}$ along the $y$-axis, which was the temperature gradient direction of $\mathrm{d} T / \mathrm{d} y$ (Figure 6(a)). Different from conventional sidewall fluid flow [28, 31], the sidewall fluid in type A was seen to have an additional velocity component $v_{\mathrm{sz}}$ along the $z$-axis. The total velocity $v_{\mathrm{S}}$ (in the sidewall groove) of type A was decomposed into $v_{\mathrm{sx}}$ and $v_{\mathrm{sz}}$, with $v_{\mathrm{sz}}$ along the temperature gradient direction of $\mathrm{d} T / \mathrm{d} z$. The above analysis suggested that the connected grooves strengthened convection in $y$ and $z$ direction. According to the field synergy principle [35], it was concluded that connected grooves improved the heat transform performance due to the connected grooves intensifying fluid convection along temperature gradients. Similar to type A, the streamline of type B was also guided to flow along the temperature gradient direction of $\mathrm{d} T / \mathrm{d} y$ in Figure 6(b). However, some center fluid in type $\mathrm{B}$ still flowed along the $x$-axis, which might have been due to the groove depth being too small to influence the center fluid. Type D was a typical sidewall groove microchannel (Figure 6(c)). Fluid was is trapped in the sidewall groove, mainly in the form of transverse vortices that have a certain disturbing effect on the groove fluid, but little effect on the central fluid. Similar findings have also been documented in a previous study [28].

\subsection{Pressure Drop}

All samples presented a monotonic increasing trend in pressure drop with increasing Reynolds number, which was consistent to many other reports. In addition, grooves also affected the flow resistance. Curves of pressure drop varying with $R e$, showed that the $\Delta P$ of grooved microchannels were significantly higher than that of

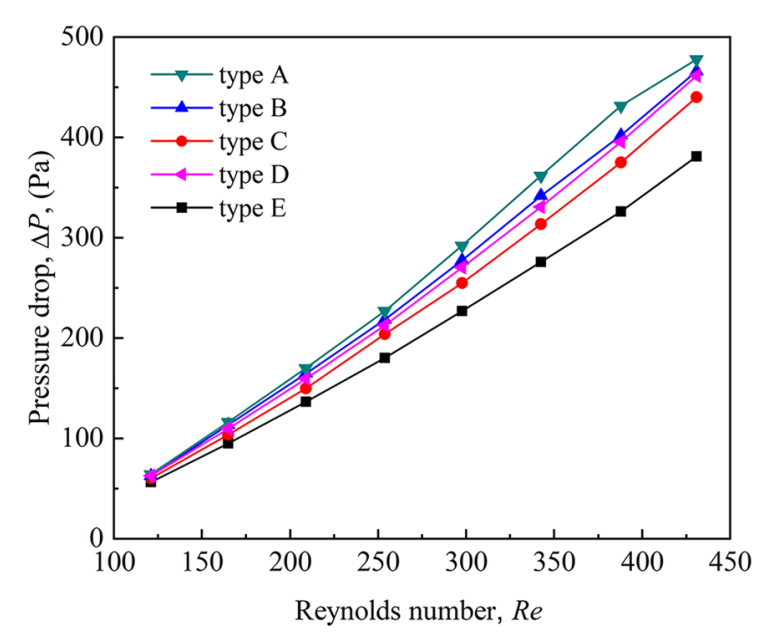

Figure 7 Curves of pressure drop vs. Reynolds number for different microchannels

smooth microchannels at the same $R e$ in Figure 7. This was because the existence of grooves led to the formation of vortices which made the fluid deviate from the mainstream direction, thus increased flow resistance. For example, the $\Delta P$ of type $\mathrm{A}$ had an average $84.3 \%$ higher than that of type $\mathrm{E}$ due to fluid vortices. Also, $\Delta P$ varied with microchannel structure, such that $\Delta P$ of type $A$ was seen to be higher than that of other grooved microchannels, as type A contained both bottom grooves and sidewall grooves. Moreover, the $\Delta P$ of type $\mathrm{C}$ was higher than that of type $\mathrm{E}$ but lower than all other grooved microchannels. The groove arrangement of type $\mathrm{C}$ has been confirmed to fit the profile of streamlining better than other types of microchannels [37]. The less fluid velocity changed, the smaller the flow resistance. Therefore, the $\Delta P$ of type $C$ was lower than that of other grooved microchannels. It was also observed that, with increased $R e, \Delta P$ differences of different microchannels became more significant, indicating that grooves had greater influence on flow resistance at high $R e$.

\subsection{Heat Transfer Performance}

The $\mathrm{Nu}$ of grooved microchannels were significantly higher than those of the smooth one under the same $R e$ (Figure 8a). The order of $N u$ values in all microchannel samples, from large to small was type $\mathrm{A}>\mathrm{B}>\mathrm{C}>\mathrm{D}>\mathrm{E}$. The $N u$ of types A, B, C, and D were $106 \%, 73.4 \%, 50.1 \%$, and $12.6 \%$ higher than that of type $E$, respectively. It was found that the average $\mathrm{Nu}$ of type A was greater than the simple superposition of types B and D $(106 \%>(73.4 \%$ plus $12.6 \%)$ ). This indicated that the heat transfer performance of type A was greater than the simple superposition of types $B$ and $D$. The reason for this was that 


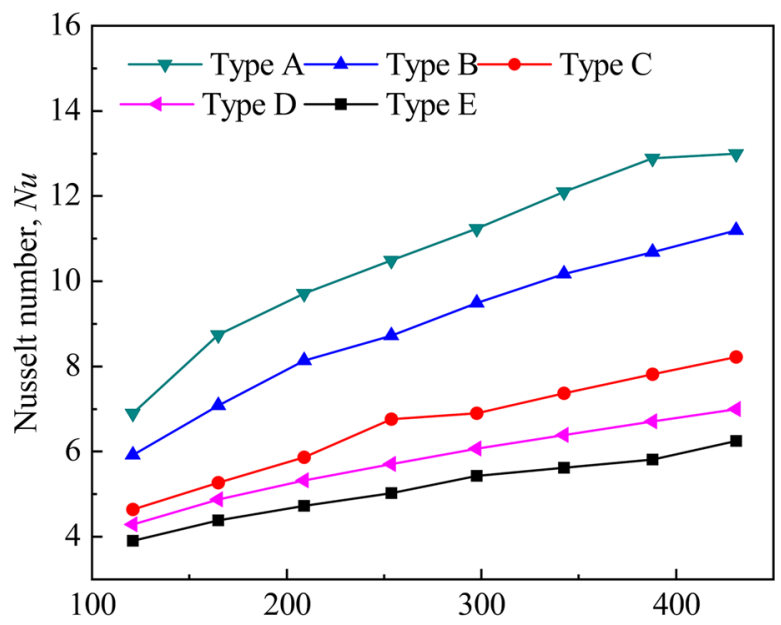

(a) Reynolds number, $R e$

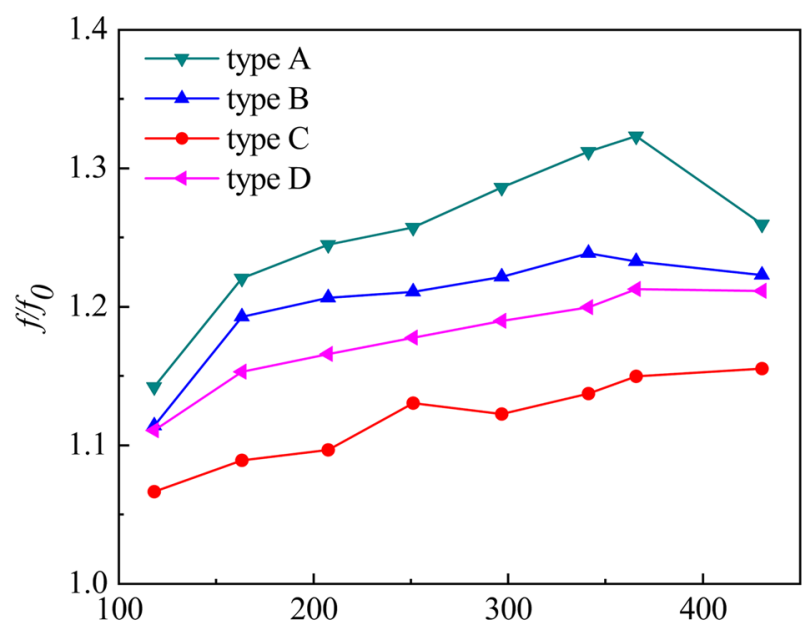

(c) Reynolds number, $R e$

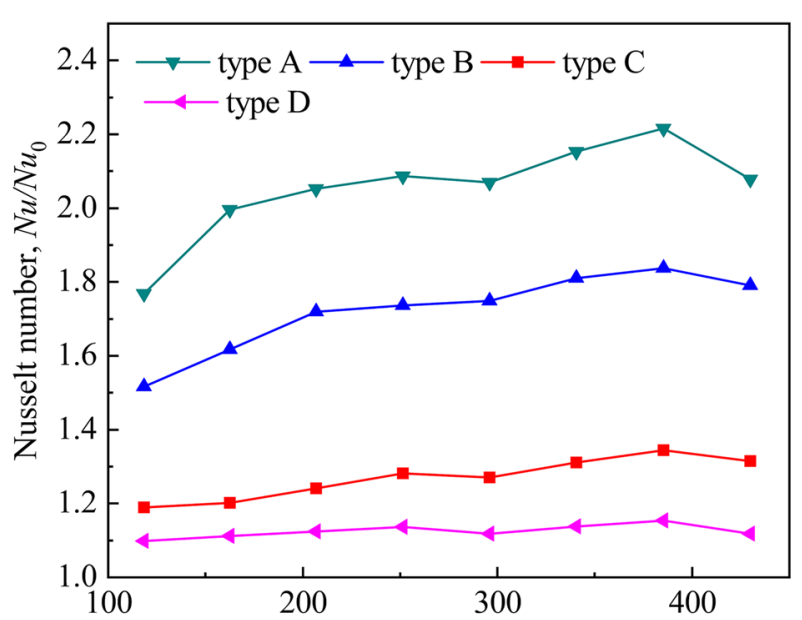

(b) Reynolds number, Re

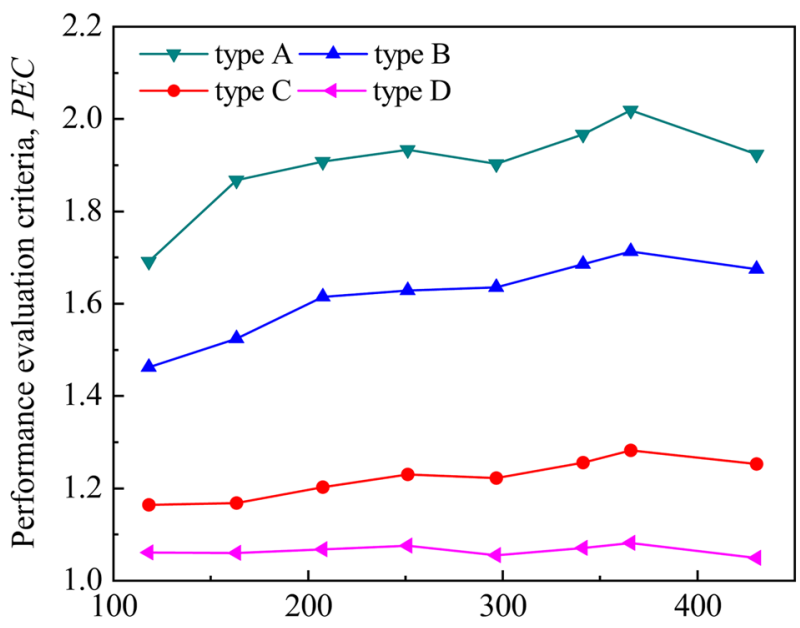

(d) Reynolds number, $R e$

Figure 8 Heat transfer performance of different microchannels: $N u, N u / N u_{0}, f / f_{0}$, and $P E C$ as a function of Re ((a-d), respectively)

the connected grooves transformed flow in the sidewalls from transverse to longitudinal vortices (with a longitudinal velocity component $v_{\mathrm{sz}}$ along the $z$-axis) based on Section 4.2. The existence of $v_{\mathrm{sz}}$ promoted the fluid at the hot boundary (bottom surface of the microchannel) to flow to the cold boundary (adiabatic upper plate). Therefore, its overall heat transfer was better than that of type D with only sidewall grooves and type B with only bottom grooves. The $\mathrm{Nu}$ of different bottom grooved microchannels, types $B$ and $C$, were also found to be larger than that of type $\mathrm{D}$, indicating that bottom grooves had a more significant effect on heat transfer than sidewall grooves.

Engineers always pursue microchannels with low flow resistance and high heat transfer performances. However, methods of heat transfer enhancement commonly are accompanied with a pressure drop penalty. $\mathrm{Nu} / \mathrm{Nu} u_{0}$ and $f / f_{0}$ reflect the differences of heat transfer performance and flow resistance between different grooved microchannels and a rectangular microchannel (Figure 8(b) and (c)). $N u / N u_{0}$ and $f / f_{0}$ almost increased with increased $R e$, and variations in $N u / N u_{0}$ and $f / f_{0}$ with $R e$ indicated that the existence of grooves led to the simultaneous enhancement of heat transfer performance and flow resistance. Thus, the optimal microchannel structure was still not obtained.

The comprehensive evaluation factor $(P E C)$ is widely used to evaluate the comprehensive performances of different microchannels. When the value of $P E C$ is $>1$, the comprehensive performance of a microchannel is effectively improved, and at other values indicates that the 


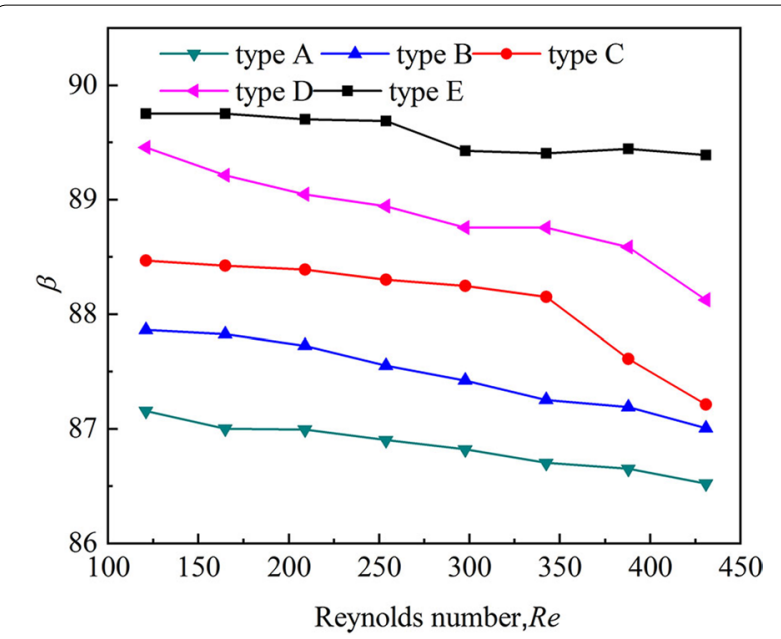

Figure 9 Field-synergy angle $\beta$ of different microchannels as a function of Re

performance is lower than or equal to that of a smooth microchannel. Here, the $P E C$ values of different grooved microchannels were all $>1$, with the order from large to small $P E C$ being type $\mathrm{A}>\mathrm{B}>\mathrm{C}>\mathrm{D}$ (Figure $8(\mathrm{~d})$ ).

The average $P E C$ values of types $\mathrm{A}, \mathrm{B}, \mathrm{C}$, and $\mathrm{D}$ were $1.90,1.62,1.22$, and 1.06, respectively, which suggested that the novel connected grooves of type A exhibited the best heat transfer performance among all present microchannels. These results indicated that, although the grooves increased microchannel flow resistance, the incremental increase in heat transfer was still greater than that of flow resistance. Meanwhile, PEC curves showed similar trends to that of $N u / N u_{0}$, showing that heat transfer enhancement was a dominant factor over the studied range of $R e$.

\subsection{Field-synergy Angles}

Many previous studies have shown that grooves have different degrees of field-synergistic characteristics [38, 39]. Variations of the synergy angle $\beta$, the angle between velocity vector and temperature gradients of the fluid, of different microchannels were examined (Figure 9). The $\beta$ value was seen to decrease with increased $R e$, while clear differences in $\beta$ were observed between different microchannels. The $\beta$ of type $\mathrm{E}$ was close to $90^{\circ}$, which was the largest field-synergy angle observed here and indicated that synergistic effects in type E were very weak, with almost no synergism. This finding was consistent with the flow analysis results (Figure 6). Among all these different microchannels, the $\beta$ of type A was the smallest and fluctuated at $\sim 87^{\circ}$, which suggested that type A had the best field-synergistic effects, thus obtaining the strongest heat transfer performance. The synergistic effect sequence

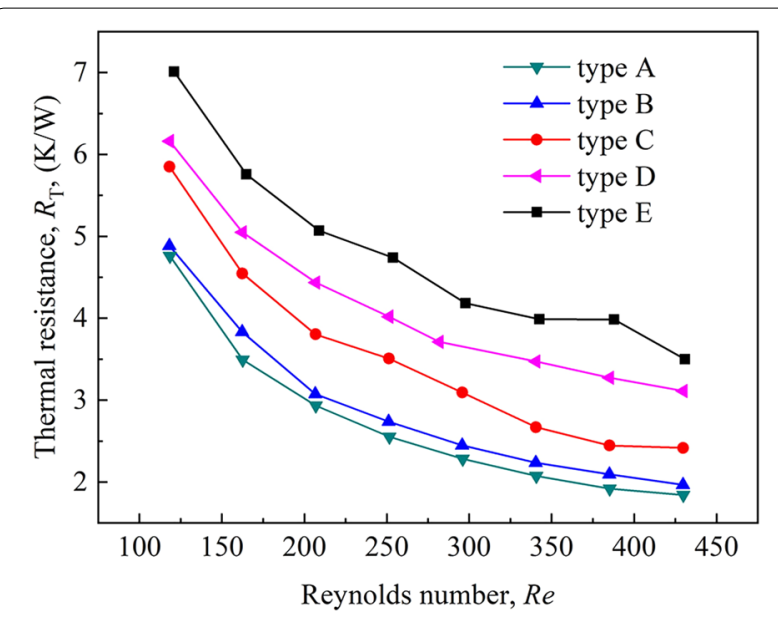

Figure 10 Thermal resistance $R_{T}$ of different microchannels as a function of Re

from large to small was type $\mathrm{A}>\mathrm{B}>\mathrm{C}>\mathrm{D}>\mathrm{E}$, which was consistent with the heat transfer analysis (Figure 8(a) Therefore, the simulation results were verified by field synergy theory $[34,35]$.

\subsection{Thermal Resistance and Wall Temperature Analysis}

Temperature uniformity plays an important role in prolonging the life of electronic components and the performance of microreactors. Microchannel heat sinks are an effective means for reducing thermal resistance and improving temperature uniformity. Curves of thermal resistance $R_{T}$ vs. Re showed that $R_{T}$ gradually decreased with increased $\operatorname{Re}$ (Figure 10). This was because of decreased average fluid temperature and increased heat transfer coefficient [22]. However, the decrement in $R_{\mathrm{T}}$ became less at higher $R e$, which was due to the pressure drop increasing quickly and heat transfer coefficient increasing slowly at higher $R e$, which implied that it was insufficient to reduce $R_{T}$ only by increasing fluid velocity. At the same $R e, R_{T}$ values of grooved microchannels were all significantly lower than that of type E, indicating better overall performance. In particular, the $R_{T}$ of type A was almost half that of type $E$, which indicated that grooves helped improve heat transfer performance. The order of $R_{T}$ from large to small was type $\mathrm{A}<\mathrm{B}<\mathrm{C}<\mathrm{D}<\mathrm{E}$, which was also consistent with the order of heat transfer performance.

\subsection{Entropy Analysis}

In the process of convective heat transfer, both heat transfer and fluid flow are irreversible processes with entropy generation. The smaller the entropy production is, the higher the energy utilization. The curves of dimensionless entropy production varying with $R e$ showed that 


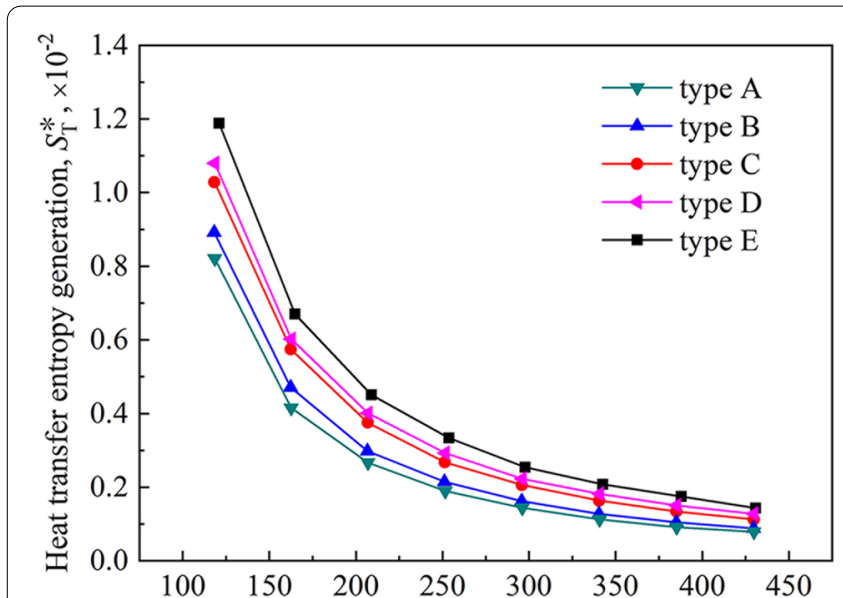

(a) Reynolds number, $R e$

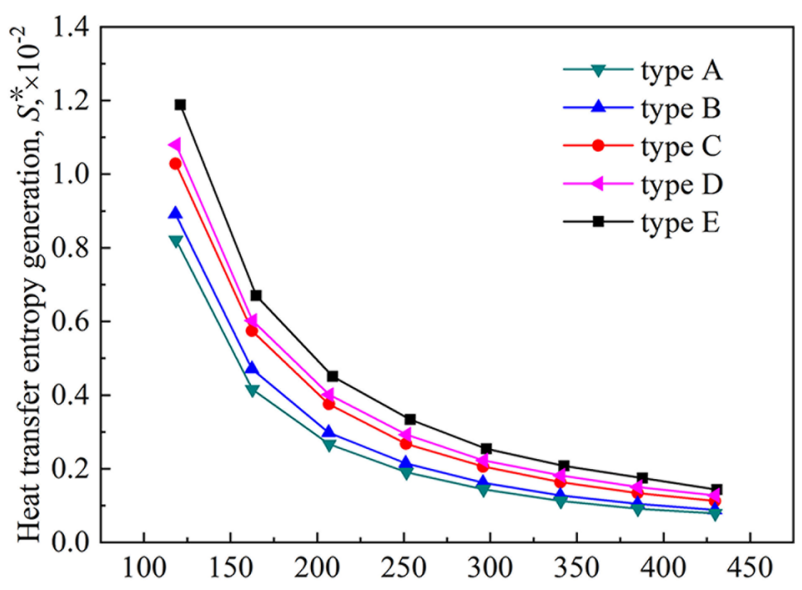

(c) Reynolds number, $R e$

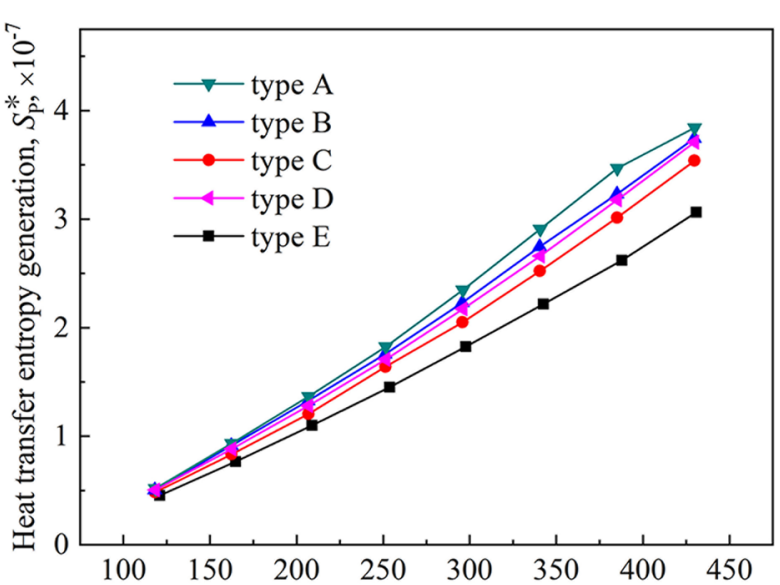

(b) Reynolds number, $R e$

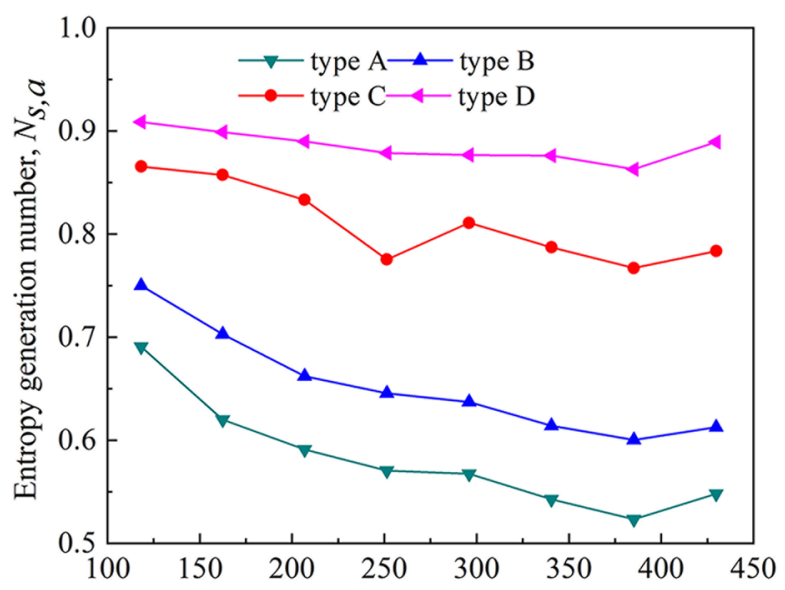

(d) Reynolds number, $R e$

Figure 11 Nondimensional entropy generation of different microchannels as a function of Re: heat transfer entropy $S_{T}^{*}(\mathbf{a})$, flowing entropy $S_{p}^{*}(\mathbf{b})$, total entropy $S^{*}(\mathbf{c})$, and entropy generation number $N_{s, a}(\mathbf{d})$

the dimensionless temperature entropy $S_{T}^{*}$ decreased with increased $\operatorname{Re}$ (Figure 11(a)). The reason for this result was that increased $R e$ led to improved heat transfer performance, resulting in more uniform fluid temperature and decreased $S_{T}^{*}$. The dimensionless flow entropy $S_{P}^{*}$ increased with increased $\operatorname{Re}$ (Figure 11(b)). The accepted reason for these results was that high flow resistance caused increased irreversible loss of heat energy at high $R e$. However, the $S_{P}^{*}$ of type E was found here to be the smallest, followed by type $C$, which was because the groove arrangement of type $\mathrm{C}$ was more in line with the microchannel groove flow trend. This finding was also consistent with the analysis of pressure drop and friction resistance (Figures 6 and $7(\mathrm{c})$ ). The dimensionless total entropy production $S^{*}$ was approximated using $S_{T}^{*}$ (Figure 11(c)), which also decreased with increased $R e$, as
$S_{T}^{*}$ was dominant in the heat transfer process. All $S^{*}$ of grooved microchannels were also observed to be lower than that of type E, followed by type B, C, D, and A. The lowest $S^{*}$ of type A indicated that the connected grooves in type A led fluid to flow along the temperature gradients, resulting in the highest energy utilization. The $N_{s, a}$ of grooved microchannels were all significantly lower than that of type $\mathrm{E}$ under the same Re, which meant that grooves improved energy utilization in the heat transfer process (Figure 11(d)). The $N_{s, a}$ of type A was also seen to be the lowest, which was in agreement with the previous conclusion that type A energy utilization was the most effective. 


\section{Conclusions}

In this study, a novel microchannel, type A, with connected grooves was designed. The heat transfer performance of type A and other microchannel types were investigated and compared via simulations with $R e$ over a range from 118 to 430 .

1) Connected grooves crossing both sidewalls and bottom surface in a microchannel were demonstrated to supply remarkable flow fields along the temperature gradients and improve heat transfer quality, compared to grooves only on sidewalls or bottom. Type A provided heat transfer efficiency superior to the simple superposition of types $B$ and $D$. The average $P E C$ values of type A, B, C, and D were 1.90, 1.62, 1.22, and 1.06 , respectively, in the studied $R e$.

2) Simulation results were also verified by field synergy theory, which showed that the synergy angle of type A was the smallest among all these microchannels, meaning that its synergistic effects were the best. Field synergy analysis results were consistent with the analysis of heat transfer performance.

3) Nondimensional entropy analysis showed that grooves can improve energy utilization and the entropy generation number $N_{\mathrm{s}, \mathrm{a}}$ of all grooved microchannels were all significantly lower than 1 . Meanwhile, the $N_{\mathrm{s}, \mathrm{a}}$ of type A was the lowest at the same $R e$, indicating that the energy utilization of connected groove microchannels was the most effective.

\begin{abstract}
Authors' Contributions
DY conceived the idea, completed the experiments, and wrote the original draft. WZ provided the funding assistance, supervised the work, and edited the draft. TF provided suggestions regarding numerical simulation. QYD assisted with the heat transfer experiment. All authors read and approved the final manuscript.
\end{abstract}

\section{Authors' Information}

Ding Yuan, is currently a postdoctoral fellow at the Department of Mechanical \& Electrical Engineering, Xiamen University, China. She received her doctoral degree from South China University of Technology, China, in 2018. Her research interests include micro and nano manufacturing technology, microchannel heat exchangers, and heat and mass transfer.

Wei Zhou, is currently a Professor at the Department of Mechanical \& Electrical Engineering, Xiamen University, China.

Ting Fu, is currently an associate professor at the Key Laboratory of Metallurgical Equipment and Control Technology, Wuhan University of Science and Technology, China.

Qinyu Dong, is currently an undergraduate at the Department of Mechanical \& Electrical Engineering, Xiamen University, China.

\section{Funding}

Supported by the Natural Science Foundation of China (Grant No. 51922092), Natural Science Foundation of Fujian Province of China (Grant No. 2017J06015), the Equipment Pre-research Foundation of China (Grant No. 61409230206), Open Fund of the Key Laboratory for Metallurgical Equipment and Control of Ministry of Education in Wuhan University of Science and Technology (Grant No. MECOF2019A01).

\section{Competing Interests}

All authors declare no competing financial interests.

\section{Author Details}

${ }^{1}$ Department of Mechanical and Electrical Engineering, Xiamen University, Xiamen 361005, China. ${ }^{2}$ Key Laboratory of Metallurgical Equipment and Control Technology, Wuhan University of Science and Technology, Wuhan 430081, China.

Received: 30 August 2020 Revised: 5 September 2021 Accepted: 27 October 2021

Published online: 20 December 2021

\section{References}

[1] D B Tuckerman, R F W Pease. High-performance heat sinking for VLSI. IEEE Electron Device Letters, 1981, 2(5): 126-129.

[2] J Huang, J H Zhang, S Y Wang, et al. Analysis of the flow rate characteristics of valveless piezoelectric pump with fractal-like Y-shape branching tubes. Chinese Journal of Mechanical Engineering, 2014, 27(3): 628-634

[3] TTChandratilleke, D Jagannatha, R Narayanaswamy. Performance analysis of a synthetic jet-microchannel hybrid heat sink for electronic cooling. 11 th Electronics Packaging Technology Conference, Shangri La, Singapore, December 09-11, 2009: 630-635.

[4] T Gan, T Z Ming, W J Fang, et al. Heat transfer enhancement of a microchannel heat sink with the combination of impinging jets, dimples, and side outlets. Journal of Thermal Analysis and Calorimetry, 2020, 141(1): 45-56.

[5] G P Zhao, Y G Jane. Heat transfer of the nanofluid in soft nanochannels under the effects of the electric and magnetic field. Power Technology, 2018, 338: 737-743.

[6] Z F Feng, X P Luo, J X Zhang, et al. Effects of electric field on flow boiling heat transfer in a vertical minichannel heat sink. International Journal of Heat and Mass Transfer, 2018, 124: 726-741.

[7] P W Higgins, C S Lengsfeld. Improving mini- and micro channel heat transfer by acoustic fields. Journal of Enhanced Heat Transfer, 2013, 20(4): 347-360.

[8] DW Fogg, KE Goodson. Bubble-induced water hammer and cavitation in microchannel flow boiling. Journal of Heat Transfer-Transactions of the ASME, 2009, 131(12): 121006.

[9] L Léal, M Miscevic, P Lavieille, et al. An overview of heat transfer enhancement methods and new perspectives: Focus on active methods using electroactive materials. International Journal of Heat and Mass Transfer, 2013, 61: 505-524.

[10] M M Sarafraz, V Nikkhah, M Nakhjavani. Thermal performance of a heat sink microchannel working with biologically produced silver-water nanofluid: Experimental assessment. Experimental Thermal and Fluid Science, 2018, 91: 509-519.

[11] D Weerapun, W Somchai. An experimental investigation on the heat transfer and pressure drop characteristics of nanofluid flowing in microchannel heat sink with multiple zigzag flow channel structures. Experimental Thermal and Fluid Science, 2017, 87: 30-39.

[12] Z Azizi, A Alamdari, M R Malayeri. Convective heat transfer of Cu-water nanofluid in a cylindrical microchannel heat sink. Energy Conversion and Management, 2015, 101: 515-524.

[13] M D Byrne, R A Hart, A K da Silva. Experimental thermal-hydraulic evaluation of $\mathrm{CuO}$ nanofluids in microchannels at various concentrations with and without suspension enhancers. International Journal of Heat and Mass Transfer, 2012, 55(9-10): 2684-2691.

[14] S M Peyghambarzadeh, S H Hashemabadi, A R Chabi, et al. Performance of water based $\mathrm{CuO}$ and $\mathrm{Al}_{2} \mathrm{O}_{3}$ nanofluids in a $\mathrm{Cu}$-Be alloy heat sink with rectangular microchannels. Energy Conversion and Management, 2014, 86: 28-38.

[15] C J Ho, L C Wei, Z W Li. An experimental investigation of forced convective cooling performance of a microchannel heat sink with $\mathrm{Al}_{2} \mathrm{O}_{3}$ /water nanofluid. Applied Thermal Engineering, 2010, 30(2-3): 96-103. 
[16] M R Sohel, S S Khaleduzzaman, R Saidur, et al. An experimental investigation of heat transfer enhancement of a minichannel heat sink using $\mathrm{Al}_{2} \mathrm{O}_{3}-\mathrm{H}_{2} \mathrm{O}$ nanofluid. International Journal of Heat and Mass Transfer, 2014, 74: $164-172$.

[17] K Anoop, R Sadr, J Yu, et al. Experimental study of forced convective heat transfer of nanofluids in a microchannel. International Communications in Heat and Mass Transfer, 2012, 39(9):1325-1330.

[18] B Rimbault, CT Nguyen, N Galanis. Experimental investigation of CuOwater nanofluid flow and heat transfer inside a microchannel heat sink. International Journal of Thermal Sciences, 2014, 84: 275-292.

[19] M Khoshvaght-Aliabadi, M Sahamiyan, M Hesampour, et al. Experimental study on cooling performance of sinusoidal-wavy minichannel heat sink. Applied Thermal Engineering, 2016, 92: 50-61.

[20] Y Fan, P S Lee, LW Jin, et al. A parametric investigation of heat transfer and friction characteristics in cylindrical oblique fin minichannel heat sink. International Journal of Heat and Mass Transfer, 2014, 68: 567-584.

[21] M Dehghan, M Daneshipour, M S Valipour, et al. Enhancing heat transfer in microchannel heat sinks using converging flow passages. Energy Conversion and Management, 2015, 92: 244-250.

[22] Z Dai, Z Zheng, D F Fletcher, et al. Experimental study of transient behaviour of laminar flow in zigzag semi-circular microchannels. Experimental Thermal and Fluid Science, 2015, 68: 644-651.

[23] J M Wu, JY Zhao, K J Tseng. Parametric study on the performance of double-layered microchannels heat sink. Energy Conversion and Management, 2014, 80: 550-560.

[24] Y Zhai, Z Li, H Wang, et al. Analysis of field synergy principle and the relationship between secondary flow and heat transfer in double-layered microchannels with cavities and ribs. International Journal of Heat and Mass Transfer, 2016, 101: 190-197.

[25] D Yuan, W Zhou, T Fu, et al. Experimental and numerical investigation of heat and mass transfer in non-uniform wavy microchannels. International Journal of Thermal Sciences, 2020, 152: 106320.

[26] Y Sui, P S Lee, C J Teo. An experimental study of flow friction and heat transfer in wavy microchannels with rectangular cross section. International Journal of Thermal Sciences, 2011, 50(12): 2473-2482.

[27] G Wang, D Niu, F Xie, et al. Experimental and numerical investigation of a microchannel heat sink (MCHS) with micro-scale ribs and grooves for chip cooling. Applied Thermal Engineering, 2015, 85: 61-70.
[28] TE Conder, S A Solovitz. Computational optimization of a grooveenhanced minichannel. Heat Transfer Engineering, 2011, 32(10): 876-890.

[29] L Chai, G D Xia, M Zhou, et al. Optimum thermal design of interrupted microchannel heat sink with rectangular ribs in the transverse microchambers. Applied Thermal Engineering, 2013, 51(1-2): 880-889.

[30] S A Solovitz, T E Conder. Flow and thermal investigation of a grooveenhanced minichannel application. Journal of Thermal Science and Engineering Applications, 2010, 2(1): 011008.

[31] P Kumar. Numerical investigation of fluid flow and heat transfer in trapezoidal microchannel with groove structure. International Journal of Thermal Sciences, 2019, 136: 33-43.

[32] A Ebrahimi, E Roohi, S Kheradmand. Numerical study of liquid flow and heat transfer in rectangular microchannel with longitudinal vortex generators. Applied Thermal Engineering, 2015, 78: 576-583.

[33] C Chen, JTTeng, C H Cheng, et al. A study on fluid flow and heat transfer in rectangular microchannels with various longitudinal vortex generators. International Journal of Heat and Mass Transfer, 2014, 69: 203-214.

[34] ZY Guo, D Y Li, B X Wang. A novel concept for convective heat transfer enhancement. International Journal of Heat and Mass Transfer, 1998, 41(14): 2221-2225.

[35] W Liu, Z C Liu, M T Zhen, et al. Physical quantity synergy in laminar flow field and its application in heat transfer enhancement. International Journal of Heat and Mass Transfer, 2009, 52(19-20): 4669-4672.

[36] J T Yang, W F Fang, KY Tung. Fluids mixing in devices with connectedgroove channels. Chemical Engineering Science, 2008, 63(7): 1871-188.

[37] A D Stroock, S K W Dertinger, A Ajdari, et al. Chaotic Mixer for Microchannels. Science, 2002, 295(5555): 647-651.

[38] N B Zheng, P Liu, F Shan, et al. Heat transfer enhancement in a novel internally grooved tube by generating longitudinal swirl flows with multivortexes. Applied Thermal Engineering, 2016, 95: 421-432.

[39] Y H Xie, ZY Shen, D Zhang, et al. Thermal performance of a water-cooled microchannel heat sink with grooves and obstacles. Journal of Electronic Packing, 2014, 136(2): 1-8.

\section{Submit your manuscript to a SpringerOpen ${ }^{\circ}$ journal and benefit from:}

- Convenient online submission

- Rigorous peer review

- Open access: articles freely available online

- High visibility within the field

- Retaining the copyright to your article

Submit your next manuscript at $\boldsymbol{\nabla}$ springeropen.com 